Volume 1, Number 2, 2015

\title{
System of Mode Variables of Energy Circuits
}

\author{
Andriy Muzychak ${ }^{*}$ \\ Lviv Polytechnic National University, 12, S. Bandera St., Lviv, 79013, Ukraine
}

Received: November 24, 2015. Revised: December 08, 2015. Accepted: December 15, 2015.

(C) 2015 The Authors. Published by Lviv Polytechnic National University.

\begin{abstract}
Modern energy systems feature diversity of elements and combination of processes and phenomena of various physical natures. Mathematical modelling of such systems relies on the tools of the theory of energy circuits. One of the major problems of this theory is formation of the unified system of interrelated variables which allow describing phenomena in circuits of various physical natures. Such a system of variables is underlain by the principle of energy analogy, which is based on the fundamental law of nature - the law of conservation of energy. The relationship between the variables is substantiated on the example of a mechanical circuit, since in mechanics both potential and kinetic energy are most illustrative. Results obtained for a mechanical circuit were then applied to circuits of other physical natures. Energy of magnetic field of the inductor is a counterpart of kinetic energy; therefore, kinetic energy in a mechanical circuit can be defined using generalized inductance. Correspondingly, energy of electrostatic field of the capacitor is a counterpart of potential energy, due to which potential energy in a mechanical circuit can be defined through generalized capacitance.
\end{abstract}

Keywords: energy circuit; metric and energy analogy; power; kinetic and potential energy.

\section{Defining the research problem selected for the study}

The level of modern energy systems (electricity supply, gas supply, heat supply, water supply, etc.) is characterized by a significantly complicated structure. They are increasingly becoming physically heterogeneous; many of them are coming to consist of elements combing multiple processes and phenomena of different physical natures.

For instance, in modern heat supply systems the heating unit of a building can contain a mixing pump, pressure regulator, heat flow rate regulator, temperature sensors (for heat-transfer medium, premises, environment) and pressure sensors (at the input and output of the unit), flow meter, electronic regulator, differential pressure regulator, as well as a feed pump, pressure regulator connected after the feed pump, etc. [1]. If the building is equipped with an individual heat supply system, then, instead of a mixing pump, in the building's engineering network there are a heat exchanger and a circulating pump [1]. As far back as fifteen or twenty years ago domestic heat supply systems were physically almost homogeneous, and the heating entrance of the building only consisted of an elevator unit or a throttling orifice. The only component of the heat supply system with a combination of processes of different physical natures at that time was a source of heat energy (heat and power plant, boiler room).

Specialized mathematical models of physically homogeneous systems are developed on the basis of the available theories of electric, mechanical, hydraulic, thermal and other circuits. Using the theory of hydraulic circuits, one can describe hydraulic status of a modern heating unit or heat supply station [2]; however, using the resources of one sectoral discipline only, heterogeneous processes of a particular element of a system cannot be covered. When physically heterogeneous processes are represented by means of the theory of electric circuits, the mathematical tools of equivalent circuits are inadequate [3].

Although the formalization of phenomena in circuits of different physical natures is the same, i.e. based on Kirchhoff's laws, and is independent from characteristics of the physical environment, a number of concepts used for

* Corresponding author. Email address: mAndriy@polynet.lviv.ua 
energy processes in electrical engineering are missing in other theories [4]. For example, in the theory of hydraulic circuits, flow rate of the medium is governed by the First Kirchhoff's law and heat flow or pressure by the Second Kirchhoff's law [5], but the concept of power does not apply, although the theory of hydraulic circuits developed on the basis of the theory of electric circuits as an allied scientific and engineering discipline [6]. In the theory of thermal circuits, the concept of power is applicable, but it is a counterpart of electric current in the theory of electric circuits, and this leads to some differences in calculating power balance. For thermal circuits power balance is equivalent to the First Kirchhoff's law, and it must be formed for each particular unit [7]. This downplays the importance of power balance as a generalized energy characteristic of the circuit and as an indicator of continuous energy generation and consumption in the circuit. In all sectoral disciplines, except for the theory of electric circuits, there is no concept of reactive and total power, distortion power, etc. [4].

So for research of modern energy systems with the aim of their adequate simulation and analysis, it is necessary to use and further develop methods of mathematical modelling of complex interrelated physical processes and phenomena. For generalized representation of the properties of system components of different physical natures, there was introduced the concept of energy circuit [8] which aims at a combined mathematical representation of different physical processes and phenomena within one mathematical model.

Creation of a unified mathematical model requires systems approach to the representation of processes in circuits of different physical natures and establishing a common theoretical base of mode variables and parameters of the elements regardless of the physical nature of the part these processes occur in.

\section{Analysis of recent publications and research on the problem}

Mathematical tools of the theory of energy circuits aims at a unified representation of physical phenomena of various natures. This requires deep mathematical abstraction characterized by strong commonality in the mathematical description of elements of different physical natures. An important role in such cases is performed by principles of analogy applicable to certain common properties, attributes or relations of otherwise different subjects and phenomena.

The identity of mathematical representation of processes in devices of different physical natures has been long known. For instance, electromechanical, electrohydraulic and electrothermal analogies have been successfully applied [9]. However, all these analogies have a physical component. Therefore, it is advisable to disregard the peculiarities of physical functioning of energy systems and to concentrate on the underlying physical laws [5].

The theory of energy circuits relies on metric analogy, which allowed putting aside the differences in elements' physical nature and focusing on their common mathematical representation. Mathematical equations and physical observations are linked by measuring devices. According to a measuring method, all variables fell into variables in series and variables in parallel $[9,10]$. To measure a value of a variable in parallel, the measuring device is connected in parallel to the circuit component. To assess a variable in series, the measuring device is connected in series to the circuit component.

An important principle of variables classification is nodal and contour properties of measurements [10, 11]. Variables in parallel are governed by the Second Kirchhoff's law and those in series by the First Kirchhoff's law. Kirchhoff's laws in reality are intrinsic to measurements [10].

These concepts disregarding physical properties allowed covering a wide range of physical systems within a unified theory.

It should be noted that in [10] the authors put forward another condition for choice of variables, according to which the product of variables in parallel and those in series should be equal to power. This requirement, also known as third Trent's condition, is the only one with physical meaning; however, it was not strict [10]. And, as shown above, this requirement has not been fulfilled in the sectoral theories.

Further development of the theory of energy circuits is associated with the classification of the whole groups of variables rather than separate pairs of variables ascribed to certain physical phenomena. And here the energy side comes to the fore.

Although nature defines a unique picture of physical processes in each part of an energy system, all these processes are governed by the fundamental law of conservation of energy [12]. 
Group classification was made on the basis of higher level integrated approach - the principle of energy analogy. According to this principle [8], [13], all variables divided into:

- action variables whose product results in power of energy dissipation in an element (first statement);

- state variables which are determined as integral characteristics of action variables; these variables correspond to different forms of energy - kinetic and potential (second statement).

According to the above principle of metric analogy, action variables are subdivided into variables in parallel and variables in series.

Thus, the first statement of energy analogy corresponds to the third Trent's condition, but in energy analogy this requirement is strict. Mathematically the third Trent's condition (first statement of the principle of energy analogy) is expressed in the form of $[8,9]$

$$
P=Y \cdot X,
$$

where $P$ is power (energy flux); $Y$ is action variable in parallel; $X$ is an action variable in series.

Combination of the principle of metric analogy and first statement of the principle of energy analogy (or third Trent's condition) has led to the development of the Bond Graph theory with graphical representation of energy systems in the form of a graph so that the arcs in bond graphs represent bi-directional exchange of power [14].

Under the second statement of the principle of energy analogy, state variables are time-variant integral characteristics of action variables and are also divided into state variables in parallel and state variables in series.

Further development of the principle of energy analogy was an attempt to obtain expressions for the two types of energy, kinetic and potential, for energy circuits of different physical natures. Forms of energy are divided in accordance with the principle of metric analogy - kinetic energy is connected with variable in series, and potential energy with those in parallel $[8,13]$. Thereat, for circuits of various physical natures, similarly to the electric circuit, the notions of generalized capacitance and generalized inductance were introduced.

Kinetic energy is determined by the generalized inductance

$$
W_{k}=L \frac{X^{2}}{2},
$$

while potential energy is defined through generalized capacitance

$$
W_{p}=C \frac{Y^{2}}{2},
$$

where $W_{k}, W_{p}$ are kinetic and potential forms of energy, respectively; $L$ is generalized inductance; $C$ is generalized capacitance.

A somewhat different approach to classifying variables of different physical natures is applied in the theory of multi-physical modelling. According to [3], these variables fall into intensive variables which change as the system size changes and extensive ones which are independent of the system size. However, this classification has not been further developed.

\section{Goal of the research}

The theory of energy circuits is aimed to solve problems of analysis of a wide range of physical systems. A significant number of such systems are mathematically equivalent to DC electric systems [15], usually non-linear ones. Examples of such systems are heat supply systems [2], water supply systems, heat-insulation system of a building [7], etc.

Non-linearity does not change the interpretation of the foregoing concepts, but the necessity of revision is dictated by specific characteristics of direct current circuits. The notions of capacitance and inductance are traditionally used in AC electric circuits, where there is a bi-directional interaction between electric current and magnetic field of the inductor or between voltage and electrostatic field of the capacitor. In DC circuits a magnetic 
field is created by current flow, but there is no retroactive effect of the magnetic field on the flow of electric current, nor is there bilateral interaction between the electrostatic field and voltage of the capacitor. Therefore, in DC circuits the notions of capacitance and inductance apply only to the processes of energy accumulation and output (magnetic field of the inductor or electrostatic field of the capacitor).

Expressions (2) and (3) cannot be directly applied in circuits of other physical natures, such as mechanical, for instance. It is necessary to determine kinetic and potential forms of energy through the parameters adopted in a circuit of a specific physical nature, which will then allow a full-scale application of the law of conservation of energy in energy circuits. On the other hand, such an approach will extend the notions of potential and kinetic energy adopted in mechanics to electric circuits.

The mathematical tools being developed can be and must be uniform for electric circuits and circuits of other physical natures, including mechanical, hydraulic, thermal, etc. Therefore, it is necessary to generalize the principles of energy analogy for circuits of various physical natures in order to create a single system of correlation between variables.

\section{Presentation and discussion of the results}

In Bond Graph theory, action variable in parallel is called effort, and action variable in series is flow rate or flow [14]. Such terminology is partially observed in branch disciplines, such as the theory of hydraulic circuits [5], theory of thermal circuits [2], etc. It is suggested that these terms be observed in the theory of energy circuits.

According to the second statement of the principle of energy analogy, as mentioned earlier, state variables are time-variant integral characteristics of action variables $[8,9]$.

State variables can be interpreted in two ways. According to [8], [13], integral characteristic of action variable alters its metric characteristic. That is, state variable being an integral characteristic of action variable in-series will be a variable in-parallel; and state variable being an integral characteristic of action variable in-parallel will be a variable in-series. However, in [9] there is no such change of metric characteristic. Such uncertainty is attributable to duality of energy circuits, according to which an action variable in-series and action variable in-parallel are often swapped (so-called metric and the classical approaches) [14]. As time variation of a variable does not cause change of its spatial characteristic, the approach [9] is more viable.

Let us introduce names and symbols for state variables.

State variable in parallel will be referred to as effort impulse or simply impulse

$$
J=\int_{t} Y d t
$$

where $J$ is impulse (state variable in parallel).

State variable in series will be referred to as quantity

$$
K=\int_{t} X d t
$$

where $K$ is quantity (state variable in series).

Thus, similarly to the system of variables of the mechanical translation circuit [9], one can build a quadrangle of bonds between the four main variables of the energy circuit (see Fig. 1).

In Fig. 1 variables in series are located on the left side, and those in parallel on the right side. One of the diagonals of the quadrangle (in opposite knots) bears action variables, and the other one state variable. In accordance with (1), product of action variables must equal power.

Next step of developing the system of variables and the relationship between them is determination of potential and kinetic energy. In [8], [9], the principle of energy analogy was based on the theory of electric circuits, after which the results obtained were extended to the circuits of other physical natures. As a result, for determining kinetic and potential forms of energy of circuits of other physical natures, the concepts of generalized inductance (2) and generalized capacitance (3) were introduced. 


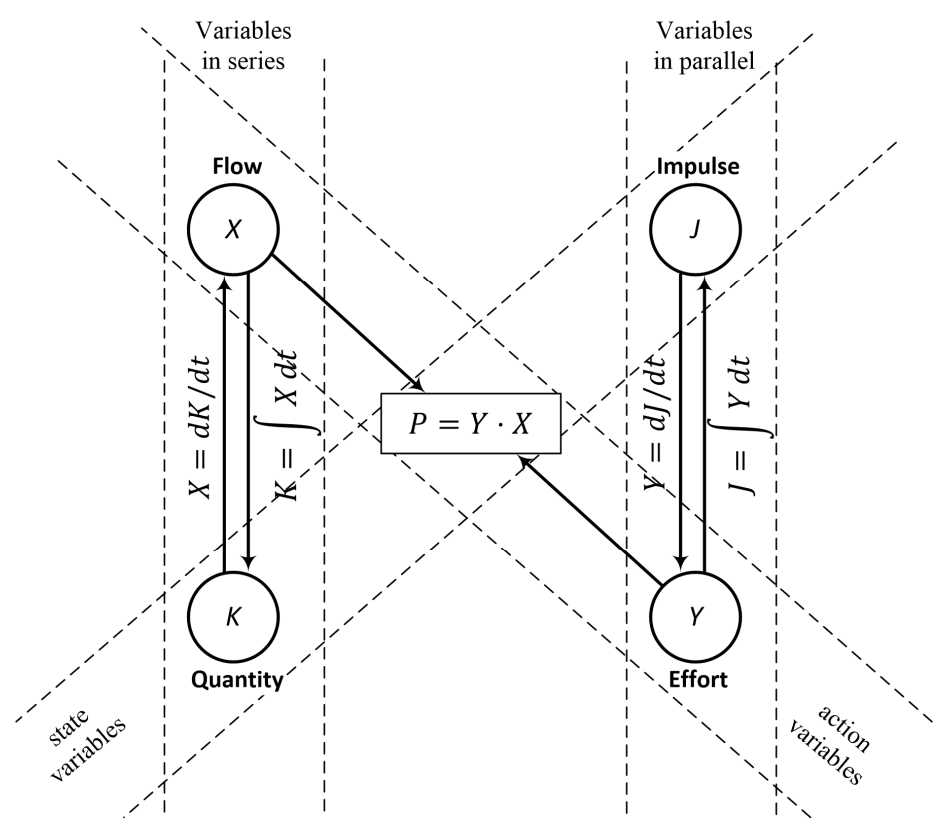

Fig. 1. Rectangle of bonds between energy circuit variables

This research relies on the opposite approach. Since kinetic and potential forms of energy are expressly present in the mechanical circuit, this is the system of variables of the mechanical circuit that the analysis is based on. The obtained results will be then extended to circuits of other physical natures, including electric ones.

In the mechanical circuit flow is speed $v$, and effort is force $F$. The list of variables of mechanical translation in the mechanical circuit and their units of measurement are presented in Table 1.

Table 1. Correspondence between energy circuit variables and mechanical translation variables in the mechanical circuit

\begin{tabular}{|c|c|c|}
\hline \multirow{2}{*}{ Energy circuit variables } & \multicolumn{2}{|c|}{ Mechanical circuit variables } \\
\cline { 2 - 3 } & Name, symbol & Unit of measurement \\
\hline \hline Action variables & & $\mathrm{N}$ \\
\hline Effort (in parallel), $Y$ & Force, $F$ & $\mathrm{~m} / \mathrm{s}$ \\
\hline Flow (in series), $X$ & Velocity, $v$ & $\mathrm{~kg} \cdot \mathrm{m} / \mathrm{s}=\mathrm{N} \cdot \mathrm{s}$ \\
\hline State variables & & $\mathrm{m}$ \\
\hline Impulse (in parallel), $J$ & Impulse, $J$ & Displacement, $l$ \\
\hline Quantity (in series), $K$ & & \\
\hline
\end{tabular}

Further considerations were based on the concepts of classical mechanics, according to which kinetic energy depends on the mass of the body and its velocity

$$
W_{k}=\frac{m v^{2}}{2}
$$

where $m$ is body mass, and $v$ is body velocity.

Thus, equation (6) contains one of the four mechanical circuit variables - velocity (action variable in series).

Kinetic energy can be represented as a product of body impulse and velocity

$$
W_{k} \equiv(m v) \cdot v=J v
$$

where $J=m v$ is body impulse.

It also confirms the compatibility of their units of measurement

$$
\left[\frac{\mathrm{kg} \cdot \mathrm{m}}{\mathrm{s}}\right] \cdot\left[\frac{\mathrm{m}}{\mathrm{s}}\right]=\left[\frac{\mathrm{kg} \cdot \mathrm{m}}{\mathrm{s}^{2}} \cdot \mathrm{m}\right]=[\mathrm{N} \cdot \mathrm{m}]=[\mathrm{J}] .
$$


In general, we are talking about energy transition from one form to another, and hence about the change of kinetic energy, so it is necessary to switch from the product to the integral. Since the body mass is invariable, the velocity changes, which is why it must be velocity integral

$$
W_{k}=\int_{v} J d v
$$

Inserting equations (7) into (8), we will obtain the result

$$
W_{k}=\int_{0}^{v} J d v=\int_{0}^{v} m v d v=\frac{m v^{2}}{2},
$$

which corresponds to (6); therefore, the proposed way of identifying kinetic energy changes is correct.

Switching symbols to those adopted in the theory of energy circuits will make it possible to formulate the rule stating that "change in kinetic energy is determined by integrating impulse (state variable in parallel) with respect to flow (action variable in series)"

$$
W_{k}=\int_{X} J d X
$$

Let us consider the way of determination of potential energy. In classical mechanics potential energy depends on the mass of the body and its height above the surface taken as null surface

$$
W_{p}=m g h
$$

where $h$ is the height of the body above the null surface.

In general, potential energy is proportional to the product of force acting on the body and body displacement

$$
W_{p} \equiv(m a) l=F l,
$$

where $F=m a$ is the force acting on the body.

Units of measurement of these variables are also compatible

$$
[\mathrm{N}] \cdot[\mathrm{m}]=[\mathrm{J}] \text {. }
$$

As in the circuit we speak about the change of potential energy, it is necessary to switch from the product to integration of displacement with respect to force (action variable in series)

$$
W_{p}=\int_{F} l d F .
$$

Inserting this in obtained equation (12) results in

$$
W_{n}=\int_{0}^{F} l d F=\int_{0}^{a} l d(m a)=\int_{0}^{a} m l d a=m a l .
$$

Since the obtained equality corresponds to (11), the proposed way of identifying potential energy is viable.

If we switch symbols to those adopted in the theory of energy circuits, it is possible to formulate the rule stating that "change in potential energy is determined by integrating quantity (state variable in series) with respect to effort (action variable in parallel)"

$$
W_{p}=\int_{Y} K d Y
$$

As a result, we obtain a complete system of variables of the energy circuit bonds between which can be display graphically (see Fig. 2). 


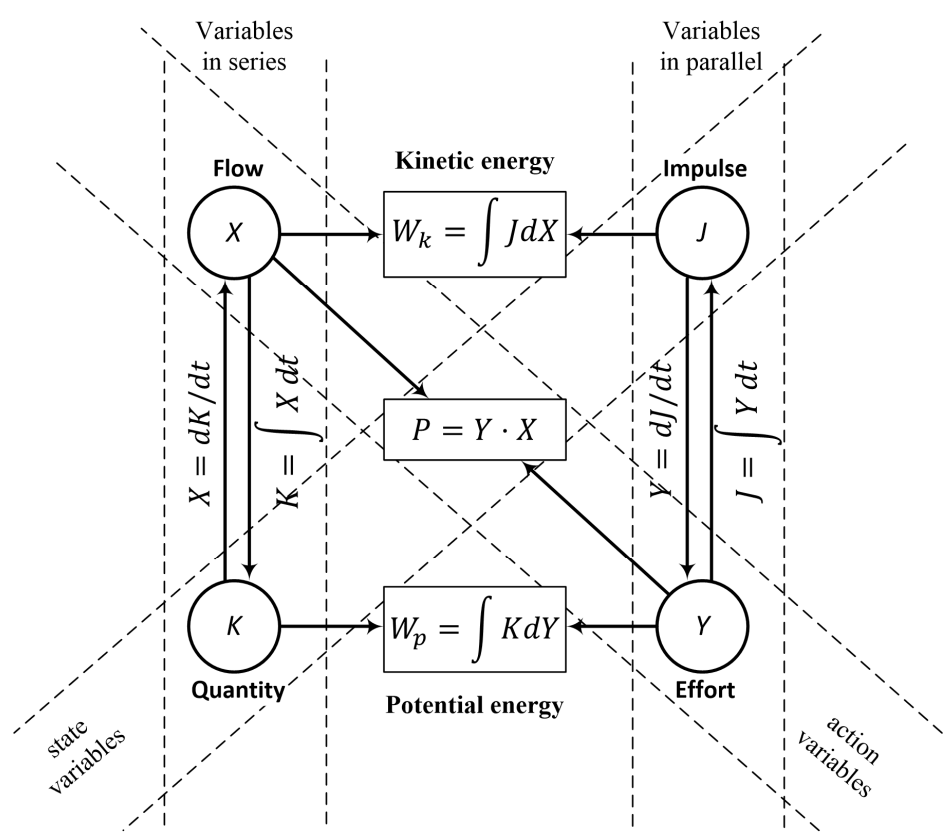

Fig. 2. Bonds between energy circuit variables.

Based on the comparison of (9) and (2), we get that for the mechanical circuit generalized inductance is equivalent to its mass

$$
L \equiv m
$$

and comparison of (14) and (3) allows identifying generalized capacitance of the mechanical circuit

$$
C=\frac{2 l}{F}
$$

It is in this relationship that the deep sense of energy analogies manifests itself - models of elements of energy circuits are based on the use of fundamental laws of preservation and conversion of energy.

The system of bonds between variables of the mechanical circuit is shown in Fig. 3, a.

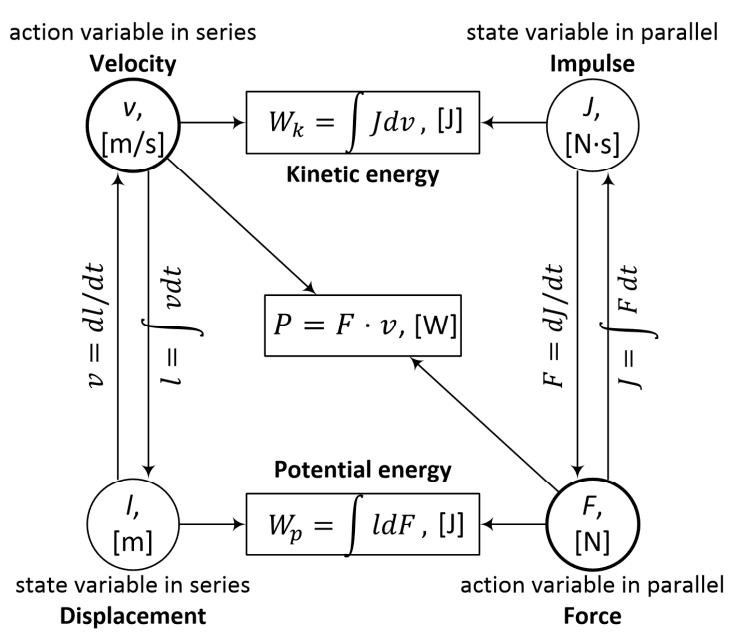

a

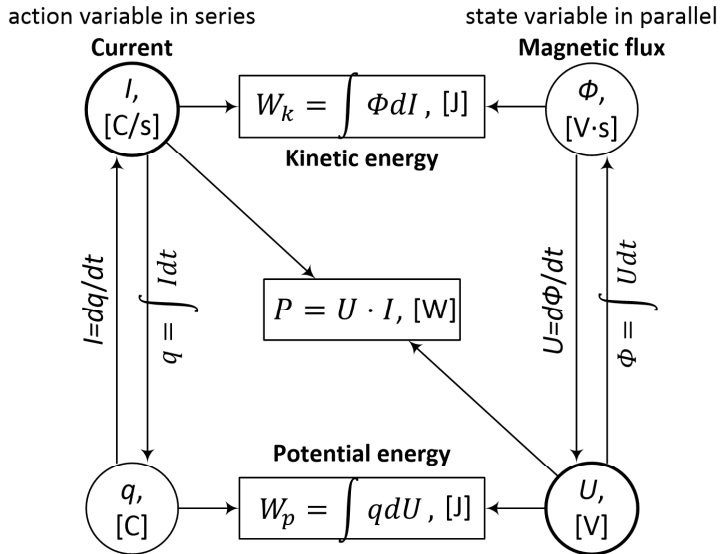

state variable in series Charge Voltage b

Fig. 3. Bonds between variables of mechanical (a) and electric (b) circuits. 
Let us go back to the electric circuit. In an electric circuit, flow is current $I$, and effort is voltage $U$. All electric circuit variables are listed Table 2 .

Table 2. Correspondence between energy circuit variables and electric circuit variables

\begin{tabular}{|c|c|c|}
\hline \multirow{2}{*}{ Energy circuit variables } & \multicolumn{2}{|c|}{ Electric circuit variables } \\
\cline { 2 - 3 } & Name, designation & Unit of measurement \\
\hline \hline Action variables & & $\mathrm{V}$ \\
\hline Effort (in parallel), $Y$ & Voltage $U$ & $\mathrm{~A}=\mathrm{C} / \mathrm{s}$ \\
\hline Flow (in series), $X$ & Current, $I$ & $\mathrm{~Wb}=\mathrm{V} \cdot \mathrm{s}$ \\
\hline State variables & & $\mathrm{C}$ \\
\hline Impulse (in parallel), $J$ & Magnetic flux, $\Phi$ & \\
\hline Quantity (in series), $K$ & Charge, $q$ & \\
\hline
\end{tabular}

The system of bonds between variables in the electric circuit is shown in Fig. 3, b.

According to (10), kinetic energy of the conductor with current going through it equals

$$
W_{k}=\int_{0}^{I} \Phi d I=\int_{0}^{I} \frac{1}{2 \pi} \frac{\mu S}{\ln (r)} I d I=\frac{1}{2 \pi} \frac{\mu S}{\ln (r)} \cdot \frac{I^{2}}{2} .
$$

where $\mu$ is magnetic permeability of the material; $S, r$ are geometrical dimensions of the path of flux closure.

So inductance in the electric circuit regarding (2) is

$$
L=\frac{1}{2 \pi} \frac{\mu S}{\ln (r)}
$$

Potential energy in the electric circuit according to (15) is

$$
W_{p}=\int q d U=q U
$$

Respectively, capacitance of the electric circuit regarding (3) is equal to

$$
C=\frac{2 q}{U}
$$

Energy of magnetic field of the inductor is a counterpart of kinetic energy, and energy of electrostatic field of the capacitor is a counterpart of potential energy.

The viability of the proposed approaches is also proved by compatibility of the units of measurement.

As for the electrical circuit kinetic energy $W_{k} \equiv \Phi I$, in units of measurement we will obtain

$$
[\mathrm{Wb}] \cdot[\mathrm{A}]=[\mathrm{V} \cdot \mathrm{s}] \cdot[\mathrm{A}]=[\mathrm{V} \cdot \mathrm{A} \cdot \mathrm{s}]=[\mathrm{W} \cdot \mathrm{s}]=[\mathrm{J}],
$$

which corresponds to the units of energy.

For potential energy $W_{p} \equiv U q$ and we obtain

$$
[\mathrm{V}] \cdot[\mathrm{C}]=[\mathrm{V}] \cdot[\mathrm{A} \cdot \mathrm{s}]=[\mathrm{V} \cdot \mathrm{A} \cdot \mathrm{s}]=[\mathrm{W} \cdot \mathrm{s}]=[\mathrm{J}],
$$

which also corresponds to energy measurement units. 
Thus, formulae for determining kinetic and potential energy proposed for mechanical circuits are applicable to electric circuits.

According to the law of conservation of energy, total energy of any component of the energy circuit is

$$
W=W_{d}+W_{k}+W_{p}
$$

where $W_{d}$ is energy dissipation (transformation of one energy form into another, for example mechanical into thermal, electric into thermal, etc.).

Let us illustrate this on the example of the mathematical pendulum (see Fig. 4, a). In its highest point, the velocity and, consequently, kinetic energy are equal to zero, due to which potential energy is maximum. In the lowest point, the position of the body of the pendulum above the null surface is equal to zero, and potential energy is zero as it transformed into kinetic energy (the velocity of the pendulum body is maximum). With time oscillations decay, as owing to air resistance part of energy is dissipated, i.e. transformed into thermal energy.

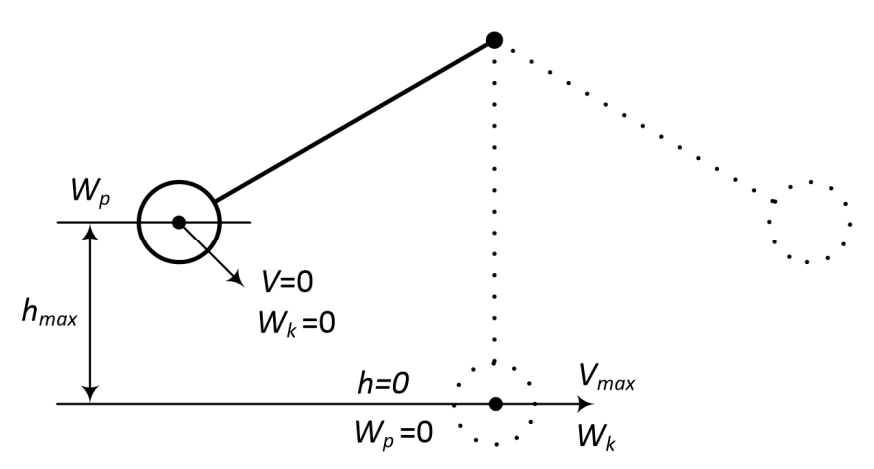

a

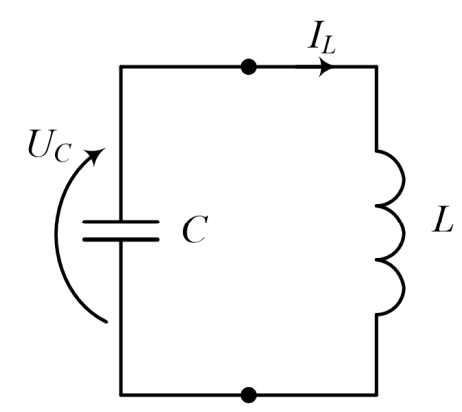

b

Fig. 4. Mathematical pendulum (a) and LC circuit (b)

A similar pattern is observed for an oscillating loop of the electric circuit (see Fig. 4, b). Here, on the reverse, electrostatic energy is transformed into magnetic one and vice versa, and irreversible dissipation of energy in resistances of the conductors takes place.

Taking into account equations (1), (10) and (15), relationship (22) finally takes the form of

$$
W=X Y t+\int_{X} J d X+\int_{Y} K d Y,
$$

where $t$ is time.

Energy of an energy circuit component consists of potential and kinetic energy with possible transformation of potential energy into kinetic and vice versa, and a component of irreversible dissipation of energy.

\section{Conclusion}

The area of application of the principle of energy analogy has been extended.

For an energy circuit of an arbitrary physical nature kinetic energy is defined as impulse (state variable in parallel) integrated with respect to flow (action variable in series), and potential energy as quantity (state variable in series) integrated with respect to effort (action variable in parallel).

Energy of magnetic field of the inductor is the counterpart of kinetic energy, and energy of electrostatic field of the capacitor is the counterpart of potential energy.

An integral system of interconnections between the energy circuit variables, which is applicable to circuits of any physical nature, has been devised.

Observance of the statements of the principle of energy analogy allows obtaining a system of variables for circuits of various physical natures adapted for use in the framework of the theory of energy circuits. 


\title{
References
}

[1] Pyrkov, V. V. (2008) Modern Heat Supply Units. Automation and Control. Taki Spravy Publishers, Kyiv, 252.(in Russian)

[2] Malinovskyi, A. A., Turkovskyi, V. H., Muzychak, A. Z. (2014) Methodology of Analysis and Improvement of Modes of District Heating Systems with Direct Connection of Consumers. Proc. of National Mining University, 1, 85-91. (in Ukrainian)

[3] Podoltsev, A. D., Kucheriavaia, I. N. (2015) Multiphysics Modeling in Electrical Engineering. Institute of Electrodynamics of the National Academy of Sciences of Ukraine, Kyiv, 305. (in Russian)

[4] Rodkin, D. I. (2010) Extended Application of Tellegen's Theorem in Problems of Electrical Engineering. Proc. of Kremenchuk M. Ostrohradskyi State University, 4(63), 98-109. (in Russian)

[5] Merenkov, A. P., Khasilev, V. Ya. (1985) Theory of Hydraulic Circuits. Nauka Publishers, Moscow, 278. (in Russian)

[6] Merenkov, A. P., Sidler, V. G., Takaishvili M. K. (1982) Generalization of Electrical Methods for Hydraulic Circuits. Electronnoye Modelirovaniye Journal, 2, 3-11. (in Russian)

[7] Malinowski A., Turkowski W., Muzychak A. (2014) Thermal Conditions of Buildings: Mathematical Modeling by Power Circuit Theory. Technical transactions Civil engineering, 3-B(8), 299-309.

[8] Saukh, S. M. (2003) Power Analogies in Theory of Power Circuits. Reports of the National Academy of Sciences of Ukraine, 12, 76-83. (in Ukrainian)

[9] Berdnikov, V. V. (1977) Applied Theory of Hydraulic Circuits. Mashinostroeniye Journal, Moscow, 192. (in Russian)

[10] Trent H. M. (1955) Isomorphism between Oriented Linear Graphs and Lumped Physical System. J. Acoustic America, 5, $500-527$.

[11] Koenig H., Blackwell W. (1961) Electromechanical System Theory. MeGraw-Hill Book Company, New-York. 424.

[12] Zahirhiak, M. V., Rodkin, D. I., Chernyi, A. P., Korenkova, T. V. (2011) Areas of Instantaneous Power Theory Development and its Application to Problems of Electromechanics. Electrotechnical and Computer Systems, 3, 347-354. (in Russian)

[13] Saukh, S. M. (2011) Mathematical modeling of power circuits. Electronnoye Modelirovaniye Journal, 33, 3, 3-12. (in Russian)

[14] Borutzky W. (2010) Bond Graph Methodology - development and analysis of multidisciplinary dynamic system models. Springer, London, 662 .

[15] Yevdokimov, A. G. (1976) Optimal Tasks on Engineering Networks. Vyshcha Shkola Publishers, Kharkiv University, 153. (in Russian)

\section{Система змінних режиму енергетичних кіл}

\author{
Андрій Музичак \\ Національний університет “Львівська політехніка”, вул. С. Бандери, 12, Львів, 79013, Украӥна
}

\section{Анотація}

Сучасні енергетичні системи характеризуються розмаїттям елементів та поєднанням у них процесів $\mathrm{i}$ явищ різної фізичної природи. Інструментом математичного моделювання таких систем $\epsilon$ апарат теорії енергетичних кіл. Однією з важливих проблем цієї теорії є утворення єдиної системи взаємозв'язаних змінних, що дають змогу описати явища в колах різної фізичної природи. В основі побудови такої системи змінних покладено принцип енергетичної аналогії, який основується на фундаментальному законі природи законі збереження енергії. Взаємозв'язок між змінними обгрунтовано на прикладі механічного кола, оскільки саме в механіці найнаочнішими є обидві форми енергії - кінетична та потенціальна. Результати, отримані для механічного кола, поширено на кола іншої фізичної природи. Енергія магнітного поля індуктивності $\epsilon$ аналогом кінетичної форми енергії, відповідно кінетичну енергію у механічному колі можна визначати через узагальнену індуктивність; а енергія електростатичного поля конденсатора - аналогом потенціальної форми енергії, відповідно потенціальну енергію у механічному колі можна визначати через узагальнену ємність.

Ключові слова: енергетичне коло; метрична й енергетична аналогія; потужність; кінетична та потенціальна форми енергії. 